\title{
Exploring the efficiency of Mexican universities: Integrating Data Envelopment Analysis and Multidimensional Scaling th
}

\author{
Marti Sagarra ${ }^{\mathrm{a}, *}$, Cecilio Mar-Molinero ${ }^{\mathrm{b}, \mathrm{c}}$, Tommaso Agasisti ${ }^{\mathrm{d}}$ \\ a Department of Economics, Universitat de Girona, Spain \\ ${ }^{\mathrm{b}}$ Department of Business, Universitat Autònoma de Barcelona, Spain \\ ${ }^{\mathrm{c}}$ Kent Business School, University of Kent, UK \\ d Politecnico di Milano School of Management, Italy
}

\begin{abstract}
A B S T R A C T
National policy initiatives require the expenditure of large amounts of resources over several years. It is common for these initiatives to generate large amounts of data that are needed in order to assess their success. Educational policies are an obvious example. Here we concentrate on Mexico's "Educational Modernisation Programme" and try to see how this plan has affected efficiency in teaching and research at Mexico's universities. We use a combined approach that includes traditional ratios together with Data Envelopment Analysis models. This mixture allows us to assess changes in efficiency at each individual university and explore if these changes are related to teaching, to research, or to both. Using official statistics for 55 universities over a six year period (2007-2012), we have generated 12 ratios and esti-mated 21 DEA models under different definitions of efficiency. In order to make the results of the analysis accessible to the non-specialist we use models that visualise the main characteristics of the data, in particular scaling models of multivariate statistical analysis. Scaling models highlight the important aspects of the information contained in the data. Because the data is three-way (variables, universities, and years) we have chosen the Individual Differences Scaling model of Carroll and Chang. We complete the paper with a discussion of efficiency evolution in three universities.
\end{abstract}

Keywords:

Performance evaluation

Benchmarking

Efficiency

Data Envelopment Analysis (DEA)

Multidimensional Scaling (MDS)

Higher education

\section{Introduction}

Mexico is the largest Spanish speaking country in the world, with a population of 112 million inhabitants according to the 2010 population census. It expects the demand for university education to increase in the future. There are two reasons for this. First, the number of individuals aged between 15 and 25 years old will increase under present trends [5]. Second, Mexico has been industrialising and this brings an increased interest in university education, something that is expected to result in a higher age participation rate, the proportion of individuals who attend university [11].

The Mexican government, aware of these trends, set up an "Educational Modernisation Programme" starting in 1989 [21,28]. As a result of this programme, public expenditure in Higher Education increased from $0.42 \%$ of GDP in 1990 and 1\% of GDP in 2010

\footnotetext{
This manuscript was processed by Associate Editor Zhu.

* Correspondence to: Department of Economics, Faculty of Business and Economic Sciences, Universitat de Girona, 17071 Girona, Spain.

E-mail address: marti.sagarra@udg.edu (M. Sagarra).
}

(OECD, 2013, Education at a Glance, table B2.3, p. 193). The modernisation plan included: financial incentives for degree quality enhancement; national planning of university places in an attempt to match supply to the needs of the country; the creation of a system of academic quality control; a "National Researchers' System" that was to provide research incentives to individuals and institutions; and the splitting of the Higher Education (HE) budget into an ordinary component with which to pay recurrent expenditure, and an extraordinary component distributed on a competitive basis [21]. The extraordinary component, which amounts to about $30 \%$ of the budget, has been aimed at improving the quality of university staff; improving university infrastructure, both in terms of lecturing and administration; widening internationalisation; purchasing better equipment; and improving the quality of undergraduate and postgraduate programmes (ANUIES 2004).

The Mexican university system is made up of a variety of institutions: there are universities financed by the central federal government, universities financed by local state governments, and private universities. In this study we analyse a sample of 55 Mexican universities over a six-year period (2007-2012): 6 federal universities, 34 local state universities, and 15 private universities. 
Using officially published data, Sagarra et al. [47] demonstrated that Mexico's policy initiative has been successful in bringing about improvements in the university system. The question still remains of whether resources are being better employed. In other words: have there been improvements in efficiency? Is it possible to assess, on the basis of published data, how the changes have affected particular institutions? Answering such questions is the aim of this study.

The present study is explicitly inserted into the stream of literature about the estimation of educational institutions' efficiency, and in particular it tries to address the challenges listed by the recent review proposed by De Witte and Lopez-Torres [7]. More specifically, we propose a methodology that combines different technologies - as efficiency scores and indicators - in order to improve the interpretability of the results.

For each individual university we have two types of information: 12 indicators (ratios) obtained from published statistics, and efficiencies obtained from 21 possible Data Envelopment Analysis (DEA) formulations. The 21 DEA models derive from all the possible combination of inputs and output available. We include 3 inputs (faculty, enrolment and first joining graduates) and 2 outputs (published papers and graduates). DEA allocates a score to each decision unit being analysed. This score depends on the inputs and outputs in the model. The estimation of a variety of specifications (combinations of inputs and outputs) makes it possible to explain in what sense any two decision units differ in the way they approach efficiency, even when the scores are equal. When the efficiency scores are different, this procedure reveals the approach to efficiency of a unit, and provides a ranking of all decision units.

The specific novelty in the estimation of models resulting from a variety of DEA specifications is that the results of the analyses can be visualised with the help of multivariate statistical analysis techniques such as Multidimensional Scaling. Indeed, although both multivariate analysis and DEA have been extensively used in the context of educational research (see $[62,25,16]$ for a review of DEA; and [43] for MDS), their joint utilisation is new in the HE context. The present study is also innovative in the sense that it uses panel data. This study is inserted in the recent stream of the literature that explores the evolution of universities' efficiency over time (see [18] for England, and García-Aracil [10] for Spain); while previous contributions assessed the relative efficiency of universities from a static perspective, here we investigate how efficiency changed in medium-term (six years). Therefore, despite the availability of several years of data, we did not decompose the efficiency change over time in the various components, such as those proposed by recent work realised by Johnson and Ruggiero [19] - namely pure efficiency change, technological improvements and time-varying environmental conditions. Indeed, the primary focus of the present work is the combination of different approaches (DEA and ratios) in a multidimensional setting for classifying universities. A closer look to results over time is then left to future research extensions, as discussed in the last section.

Policy analysis in cases such as this one presents serious challenges. The results have to be understood by policy makers who are intelligent people but are not necessarily versed in advanced statistical or optimisation tools. Besides, there are very many universities to be studied - in this case it amounts to 55, but the total number could be much larger if all private universities had been included - and a method has to be developed that allows the assessment of change in each individual university. We present here a methodology that addresses both objectives.

We analyse the data using scaling techniques, in order to visualise the results and make them accessible to policy makers. The methodology permits the merging of qualitative and quantitative information in policy analysis. Since we deal with three-way (panel) data, the technique chosen was the Metric Individual Differences Scaling of Carroll and Chang (INDSCAL) (see [3]). We chose the metric approach rather than the ordinal version of the algorithm, in order to separate aspects that remain invariant during the studied period from aspects that changed from year to year. In this study, ratios and DEA specifications have been taken as variables, and universities as cases. The study of each individual university has taken place using the "Property Fitting" technique, a regression-based approach that shows how each university has evolved in the space of ratios and efficiencies. Although all the universities have been explored using the methods described here, we only give three examples in way of illustration: a federal university, a local state university, and a private university. Although these examples have been chosen as representative of the different university categories, the analysis has proven valid in the case of all the universities included in the data set.

After this introduction we discuss the data that was employed in the study. This is followed by a technical section that describes three way scaling models, as these are not normally found in educational research. An analysis of the data, one year at a time follows next in order to identify the main characteristics of the Mexican educational system. The results of the full analysis, with the complete data set, follow next. The paper ends with a discussion of three case studies and a conclusion.

\section{Data}

Data was obtained for all universities for which there was available public information during the six-year period 20072012. This includes 6 federal universities, 34 local state universities, and 15 private universities. The data set includes all but one federal universities, all but one local state universities, and many private universities. Together, these account for about $60 \%$ student enrolment in Higher Education in Mexico.

Private universities were included if they had submitted data in order to qualify for state support for academic improvement programmes. We still do not have data for some private universities but we do not think this is a major concern, as the private universities for which no data is available did not seek state support for academic improvement programmes. We consider that our data set is almost the whole population of the universities that should be analysed. To be on the safe side, we also estimated efficiencies using the bootstrap procedure of Simar and Wilson [53], and the results were almost identical to the results reported here.

Two data sources have been used. The first source is the "Comparative Study of Mexican Universities" [57], an on-going project that systematically collects data from Mexican Higher Education Institutions; http://www.ecum.unam.mx/. However, this comparative study did not contain disaggregated information by discipline - Health, Social Sciences, Sciences, and Humanities and Education. Such information was obtained from our second source, the Mexican National Association of Universities and Higher Education Institutions (ANUIES).

The data was converted into ratios in order to make the results independent of size. Table 1 shows and defines the ratios that were calculated from the raw data for each university. These ratios attempt to describe the employment structure of faculty staff (FTEFTot), the research productivity of faculty staff (ScopusF and ScopusEn), the composition of the student body in terms of the discipline studied (EnrolLi, EnrolMa, HealthG, SocialG, ScienceG, and HumanG), success and drop-out rates (SuccessGFj and SuccessGEn), and to account for the possibility of non-linear effects we also include a measure of university size (TotalEnrol). 
Table 1

Definition of the 12 ratios calculated from the raw data.

\begin{tabular}{ll}
\hline Ratio & Ratio description \\
\hline FTEFTot & Full time equivalent faculty/total faculty \\
ScopusF & Scopus papers/full time equivalent faculty \\
ScopusE & Scopus papers/total enrolment \\
EnrolLi & Enrolment (Licentiate)/total enrolment \\
EnrolMa & Enrolment (Master)/total enrolment \\
HealthG & Graduates (Health)/total graduates \\
SocialG & Graduates (Social Sciences)/total graduates \\
ScienceG & Graduates (Sciences)/total graduates \\
HumanG & Graduates (Humanities \& Education)/total graduates \\
SuccessGFj & Success ratio: total graduates/first joining students \\
SuccessGEn & Success ratio: total graduates/total enrolment \\
TotalEnrol & Size: total enrolment \\
\hline
\end{tabular}

The ratios listed in Table 1 make it possible to describe individual universities, and to create rankings, based on one or multiple indicators. Some ratios, such as ScopusF, can be described as efficiency-related; however, for making the efficiency judgment more complete and robust, we prefer to approach it from the DEA point of view. DEA has long been used to assess efficiency in the context of Higher Education. For some early examples see, for example, [1]; and Diamond and Medewitz [9].

The specification of a DEA model requires a decision on which inputs and outputs it should include. This has been a matter of concern for a long time since DEA scores are affected by the inclusion or exclusion of an input or an output; Parkin and Hollingsworth [39]; Jenkins and Anderson [14]. The usual balance between parsimony and information redundancy applies in the case of DEA. On the one hand, we would like to have simple models that contain all the relevant information in the system under investigation, but we are worried about the exclusion of relevant variables. On the other hand, we do not want to include irrelevant variables in the model in order not to end with a pro-blem of overfitting.

Some of the first authors to address this dilemma are Norman, Stocker [37] who suggested that the impact of a particular input or output on efficiency results can be assessed by estimating efficiencies without such variable, and correlating efficiency scores with the values of the omitted variable. Pastor et al. [40] went further along this line by suggesting a systematic procedure for specifying a DEA model; they assessed the impact on the efficiency of a particular decision unit of the inclusion or exclusion of a variable, and used statistical analysis to summarise this impact. However, these approaches, although useful in the selection of a model specification do not explain in which way a particular specification reveals the strengths and weaknesses of a particular unit under assessment. Such problem was addressed by SerranoCinca and Mar-Molinero [50] who estimated a variety of specifications and analysed the results by means of multivariate statistical analysis. This idea of estimating a variety of models in order to obtain further information has been also adopted, amongst others, by Liu and Lu [27] who used a network-based approach to reveal the features of the results.

In this paper we apply the method suggested by Serrano-Cinca and Mar-Molinero [50]. Rather than use a single DEA specification, which allocates a score to each university, we prefer to go beyond a score, and explore the reasons why a university has achieved a particular DEA value. This we do by estimating a variety of DEA specifications - where specification is to be understood as a particular combination of outputs and inputs - and doing multivariate analysis of the results. Examples of the use of this approach are [49]; and Gutiérrez-Nieto et al. [12]. Estimating a variety of specifications has been done before in the context of Higher
Table 2

Inputs and outputs in the DEA model.

\begin{tabular}{llll}
\hline Inputs & & Outputs & \\
\hline A & Full time equivalent faculty & 1 & Scopus papers \\
B & Total enrolment & 2 & Graduates \\
C & First joining graduates & & \\
\hline
\end{tabular}

Education, although not in a systematic manner, an example being Tomkins and Green [55].

In the context of this paper, the use of alternative DEA specifications - i.e. combining inputs and outputs in several different ways - can serve two objectives at the same time. On one side, the approach is useful for testing the robustness of results, by exploring how sensitive is the distribution of efficiency scores to the various specifications. On the other side, a numerous set of efficiency scores provide a wider set of information for classifying and clustering the units of observations (in this case, universities) in the Multidimensional Scaling procedure (see also next section).

The choice of variables for the DEA analysis has been based in an attempt to capture the inputs and outputs of the two main activities of a university: teaching and research. The literature in this field agrees to consider human and financial resources as inputs, measuring them for instance through the number of academic staff, expenditure per student, and similar. In this sense, universities are considered as multiproduct organisations that produce the outputs using the inputs jointly [54]. On the output side, the preference goes to the number of publications and grants (for research), and to graduates (as for teaching). The debate about the proper measurement of inputs and outputs has a long history; Beasley [2] discussed it in a subject-specific context, Johnes and Johnes [15] has some early discussion with specific attention to research; Johnes [17] provides a comprehensive description of the various aspects of measuring HEIs' efficiency when using DEA.

In this paper, based on data availability we have chosen as inputs the number of full-time equivalent faculty, total enrolment, and number of first joining students. A main driver of university finances is the total number of students enroled, and this is why we have also included the number of enroling students as an input. It would have been better to use actual budgets but these were not available for private universities. As outputs we have included the number of Scopus papers, and the number of grad-uates. The number of Scopus papers is related to the success of the research activity, and the number of graduates is related to the success of the teaching activity.

Rather than estimating a single DEA model that includes all the inputs and all the outputs, we have estimated DEA scores for 21 combinations of inputs and outputs. The DEA scores have been calculated using an input-oriented variable returns to scale (VRS) models Table 3 shows the list of such combinations, that we have named "specifications".

In conclusion, the full data set consists of a set of ratios and a set of DEA scores for each university and for each year. This data set will be analysed using multivariate statistical methods.

\section{Methodology}

\subsection{Three-way scaling models}

The data are analysed by means of multivariate statistical techniques. Ratios and DEA scores are treated as variables, making a total of 33 variables: 12 ratios and 21 DEA specifications. There may appear to be an element of heterogeneity by mixing ratios with DEA results, but it is in order to remember that DEA 
Table 3

DEA specifications.

\begin{tabular}{lll}
\hline Specification & Inputs & Outputs \\
\hline A1 & A & 1 \\
AB1 & A,B & 1 \\
ABC1 & A,B,C & 1 \\
AC1 & A,C & 1 \\
BC1 & B,C & 1 \\
B1 & B & 1 \\
C1 & C & 1 \\
A2 & A & 2 \\
AB2 & A,B & 2 \\
ABC2 & A,B,C & 2 \\
AC2 & A,C & 2 \\
BC2 & B,C & 2 \\
B2 & B & 2 \\
C2 & C & 2 \\
A12 & A & 1,2 \\
AB12 & A,B & 1,2 \\
ABC12 & A,B,C & 1,2 \\
AC12 & A,C & 1,2 \\
BC12 & B,C & 1,2 \\
B12 & B & 1,2 \\
C12 & C & 1,2 \\
\hline
\end{tabular}

*(A, B, C, 1 and 2 as specified in Table 2$)$.

efficiency can also be written in the form of a ratio of weighted outputs divided by weighted inputs. There is, in fact, a body of literature that links ratios and DEA models; Liu et al. [26]; Chen and McGinnis [4]; Premachandra [44]. In fact, a DEA model with only one input and one output is closely related to a ratio. They are not totally equivalent, as the DEA model is bounded in the zero to one range, and the ratio is not. Besides, a DEA efficiency is the result of a set of multiple comparisons between observed units, whilst a ratio does not take into account the rest of the data.

Universities are treated as observations. There are six matrices in total, one for every year. This is three-way data: variables (ratios and DEA scores), observations (universities), and years. Techniques for the analysis of three way data have been available for a long time; Kiers [22]. Examples are Tucker's [56] extension of factor analysis, Harshman's [13] parallel factor analysis, Ramsay's [45] MULTISCALE, and the Individual Differences Scaling (INDSCAL) model of Carroll and Chang [3].

Amongst the family of multivariate methods, we have chosen scaling models because they visualise the main characteristics of the data. This has the advantage of making the results accessible to the non-specialist, although technical expertise is needed in order to understand the mathematics behind the algorithms. Scaling models have been used before in the context of educational research; Sagarra et al. [46], Mar-Molinero and Portillo [35], MarMolinero and Mingers [34], and [30,31].

Scaling models work on the basis of measures of proximity between pairs of objects. If the proximity is high, the objects are located close to each other in the statistical representation. If the proximity is low, they are located far apart. This is very much the way in which other techniques, such as Factor Analysis (FA) or Principal Components Analysis (PCA), work. But FA and PCA use correlation coefficients as a measure of proximity. Scaling models can also use correlations as measures of proximity and when they do, the results obtained tend not to be very different from the results obtained with FA. But many other measures of proximity are available, something that makes scaling models more general than FA and PCA [59,6].

Proximities can be calculated between variables or between cases (in this case, universities). In this study, proximities are calculated between variables since the relationship between variables is expected to be stable over time. For example, we expect the relationship between the ratios Full time equivalent faculty/Total faculty (FTEFTot) and Total graduates/Total enrolment (SuccessGEn) to remain stable over time on the grounds that universities are slow to change their employment policies or their drop-out rates. On the other hand, we expect the degree of proximity between universities to change over time as a result of success, or lack of it, in their quest for efficiency and productivity. Indeed, the objective of this study is to identify the relative evolution of universities and to explain the reasons behind the change.

Scaling models can be metric or ordinal. Metric models use the actual value of the proximity data and preserve their ratio properties. This is to say, if the measure of proximity between objects $A$ and $B$ is double than the proximity between objects $C$ and $D$, the algorithm will attempt to place objects in the statistical map in such a way that the distance between $A$ and $B$ is twice the distance between $C$ and $D$. The alternative way of proceeding is to use relationships of order; i.e., if the measure of proximity between $A$ and $B$ is larger than the measure of proximity between $C$ and $D$, the distance in the representation between $A$ and $B$ will be larger than the distance in the representation between $C$ and $D$. Ordinal versions are more general than metric versions and are less prone to be influenced by extreme values, but metric versions are regressionbased and generate useful fit statistics. The quality of fit in metric versions is assessed by means of $R^{2} . R^{2}$ measures the variance explained by the model. In the non-metric version of scaling models, the usual practice is to measure quality of fit in terms of the variance not explained by the model. There are var-ious statistics that summarise this unexplained variance, but the most common one is known as "stress"; Coxon [6]; Kruskal [23]; Kruskal and Wish [24]; Schiffman et al. [48].

The metric three-way scaling model INDSCAL has been used to model the data set. The metric INDSCAL model produces two outputs: a "consensus map or common map", which is a kind of average over all proximity matrices, and a set of weights that indicate how individual matrices differ from the consensus map. In other words, the algorithm will return a map that reflects what remains invariant over time, and a set of weights that will contain information about change over time.

The axes of the common map usually have an interpretation in the context of the problem analysed. Each axis is associated with a weight that indicates the importance (salience) of the characteristic for that particular matrix. When the weights associated with a matrix do not differ from the weights associated with another matrix, the data for both matrices can be pooled. A discussion about weights in the context of three-way MDS models can be found in Jones [20].

The issue still remains of how to assess if two weight structures are equivalent. Given a particular data matrix, the weights can be represented as a vector in a space of as many dimensions as there are axes in the configuration. There will be one such weight for each dimension in each data matrix. It is possible to think in terms of a weight structure for the average of all the data. Such average weight will be a vector at $45^{\circ}$ of the axes. The angle between the vector associated with the average weight, and the vector asso-ciated with a particular data matrix will indicate how different the particular matrix is from the average, or how "weird" it is. The coefficient of weirdness is derived from this angle. When the weirdness coefficient is zero, both the average for all data sets and the individual map for a particular matrix coincide, and the par-ticular matrix is well represented by the common space. Young

[60] gives a mathematical description of the procedure.

All the calculations have been done with the ALSCAL routine of the computer package SPSS, version 20. 


\section{Preliminary analyses}

Prior to performing the INDSCAL analysis each yearly matrix was separately modelled using the Principal Components approach to Factor Analysis. This was done in order to establish the dimensionality of the data, since we need to decide in how many dimensions the INDSCAL configuration is to be estimated. The full data set was also analysed without taking into account yearly effects.

The results were found to change very little from matrix to matrix. Seven, or six, principal components, depending on the data set, were associated with eigenvalues higher than 1 using the Kaiser criterion, although when the seventh eigenvalue exceeded the value of unity it did so only marginally. In general, the first two principal components accounted for about $60 \%$ of the variation in the data.

To interpret the meaning of the components we rotated the factors using the Varimax method. The first two factors were always associated with efficiency, one of them with efficiency in teaching and the other with efficiency in research; which one was associated with the first factor and which one with the second factor depended on the data set. This is not a surprising result since 21 out of the 33 variables in the data set were derived using DEA. The remaining factors were found to be associated with the disciplinary orientation of the university - Social Sciences, Science, Health, or Humanities -, with the master or undergraduate degree orientation, and with the relationship between total enrolment and the number of graduates. In the following section, we find that the picture emerging from the analysis of individual matrices is confirmed by INDSCAL.

In this paper we are concerned with efficiency in teaching and research, and in the way in which efficiencies change. We are, therefore, interested in the story that emerges from the first two factors. It is obvious that more than two aspects are necessary in order to describe a university, and that the other factors are relevant in every case. But factors have the property of being uncorrelated, hence we can safely omit the study of factors other than the first two when studying the evolution of efficiency in the universities under analysis. This property also extends to the INDSCAL algorithm that we will discuss in the next section.

\section{INDSCAL model estimation and results}

Following the results of the two-way analyses, the ALSCAL algorithm was run in order to produce a configuration in a sixdimensional space. The quality of the results is measured in twoways, either through a $R^{2}$ statistic, or through a measure of Stress. The $R^{2}$ gives information about the model ability to reproduce the original data, while the measure of Stress is related to the unexplained variation in the data. A good fit will be reflected in a high value of $R^{2}$ and in a low value of the Stress statistic. ALSCAL gives these statistics for the full data set and for individual year matrices. Table 4 shows the results obtained.

As can be seen in Table 4, the results are very good from the statistical point of view, with no matrix being badly represented in the model, and no $R^{2}$ value below 0.9 .

Table 5 gives information about the weights in the INDSCAL model. The actual value of the weights is not of particular relevance, as these are scaled so that the sum of the squared values of the weights for a particular matrix is equal to the value of the $R^{2}$ for that matrix. What is important is the relative value of the weights for two different dimensions; i.e., the way in which the ratio of one weight over another one changes from year to year. We see that, if we concentrate on the relative values of the weights for pairs of dimensions, there are no great variations across the
Table 4

Goodness of fit statistics for the three-way scaling model.

\begin{tabular}{lll}
\hline Year & Stress & $R^{2}$ \\
\hline 2007 & 0.084 & 0.933 \\
2008 & 0.083 & 0.931 \\
2009 & 0.076 & 0.940 \\
2010 & 0.073 & 0.949 \\
2011 & 0.083 & 0.948 \\
2012 & 0.097 & 0.912 \\
All data & 0.083 & 0.935 \\
\hline
\end{tabular}

Table 5

Subject weights (years 2007-2012).

\begin{tabular}{lllllllll}
\hline Year & Weirdness & Dim1 & Dim2 & Dim3 & Dim4 & Dim5 & Dim6 \\
\hline 2007 & 0.115 & 0.521 & 0.420 & 0.420 & 0.323 & 0.316 & 0.323 \\
2008 & 0.050 & 0.516 & 0.476 & 0.401 & 0.338 & 0.329 & 0.234 \\
2009 & 0.079 & 0.545 & 0.481 & 0.372 & 0.318 & 0.360 & 0.209 \\
2010 & 0.102 & 0.611 & 0.493 & 0.389 & 0.279 & 0.251 & 0.200 \\
2011 & 0.062 & 0.570 & 0.459 & 0.358 & 0.315 & 0.325 & 0.283 \\
2012 & 0.074 & 0.620 & 0.433 & 0.366 & 0.297 & 0.275 & 0.203 \\
Overall importance & & 0.320 & 0.213 & 0.148 & 0.098 & 0.097 & 0.061 \\
of each dimension & & & & & & & & \\
\hline
\end{tabular}

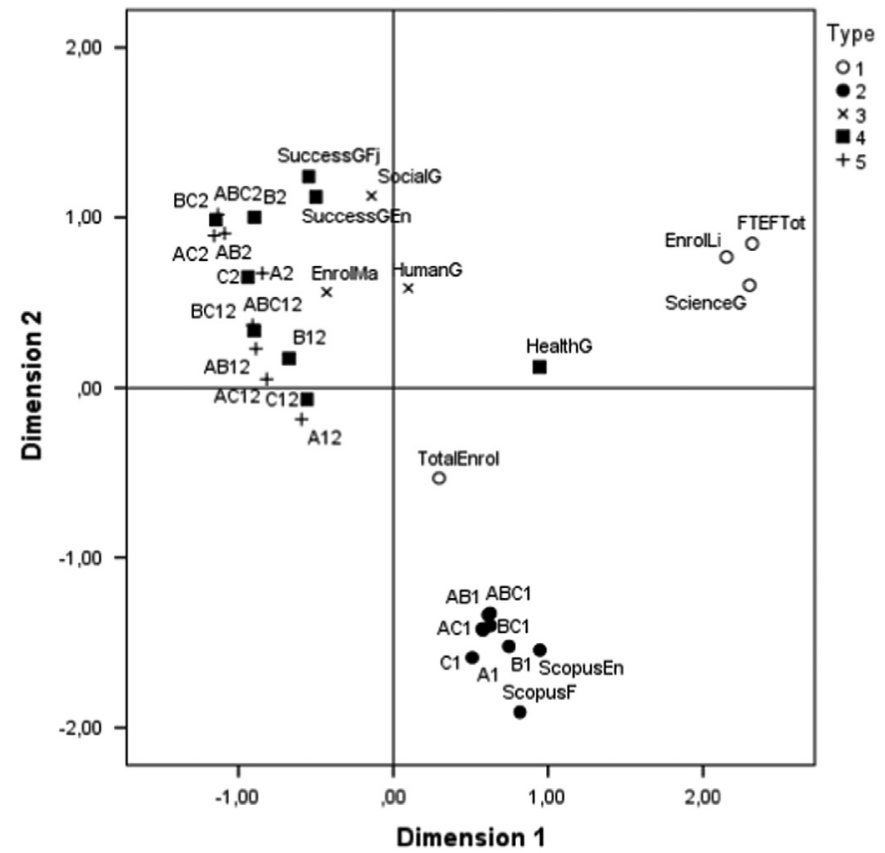

Fig. 1. INDSCAL: common map - projection on Dimension 1 (horizontal axis) and Dimension 2 (vertical axis).

different matrices. This is confirmed by the value of the Weirdness coefficient. When there is no difference between the individual year matrices and the overall matrix, the weirdness coefficient takes the value zero $[29,61]$. We conclude from the results in Table 5 that the "consensus" configuration (common map) appropriately represents the relationship between the variables over the period studied, and that there are not large time-dependent changes.

The consensus configuration is a map in a six dimensional space. This makes it impossible to represent it on the plane. We need to resort to projections on pairs of dimensions. Fig. 1 shows the projection of the consensus configuration (common map) on Dimension 1 and Dimension 2. 
Unlike configurations derived using Ordinal Multidimensional Scaling of two-way data, metric INDSCAL configurations are not rotation invariant. But it has long been observed that meaningful interpretations of the dimensions can normally be found.

It is to be noticed in Fig. 1 that efficiency models that contain output 2 (graduates) are located at the top of the map whilst efficiency models that contain output 1 (research papers) are located at the bottom of the figure. This suggests that Dimension 2 could be interpreted as "orientation towards efficiency in teaching versus orientation towards efficiency in research". This interpretation would be supported by the fact that teaching success ratios - total graduates/first joining students (SuccessGFj) and total graduates/total enrolment (SuccessGEn) - are located towards the top of Fig. 1, whilst ratios that are associated with research Scopus papers/Full time equivalent faculty (ScopusF) and Scopus papers/total enrolment (ScopusEn) - are to be found at the bottom of the figure.

Concentrating now on Dimension 1, we can see that at the far right of the first dimension we find the ratios graduates in sciences/total graduates (ScienceG), moving towards the left we find Health graduates/total graduates (HealthG). Further left we first find Graduates in Humanities and Education/total graduates (HumanG) and Social Sciences graduates/total graduates (SocialG). Thus, the "discipline orientation" of the university puts itself forward as a label for Dimension 1. The third dimension appears to be associated with the size of the university and with student/staff ratios (the projection of the six-dimensional configuration into Dimension 2 and Dimension 3 can be seen in Fig. 2). We have not attempted to attach meaning to the remaining dimensions since, for the purposes of this study, efficiency related effects can be well described using Fig. 1 and, has been argued before, orthogonality between the dimensions implies that if there is an efficiency story to be found, it will be found in the first two dimensions.

Before moving on to further analysis, we must remember that the points in Fig. 1 and Fig. 2 (ratios and efficiencies) are only projections of a six dimensional configuration on a twodimensional space. It is relevant to assess how far in the space two different points are situated, since it is perfectly possible for two points to be far apart in the space but very near to each other in Fig. 1 or in Fig. 2. To achieve this purpose, we have resorted to

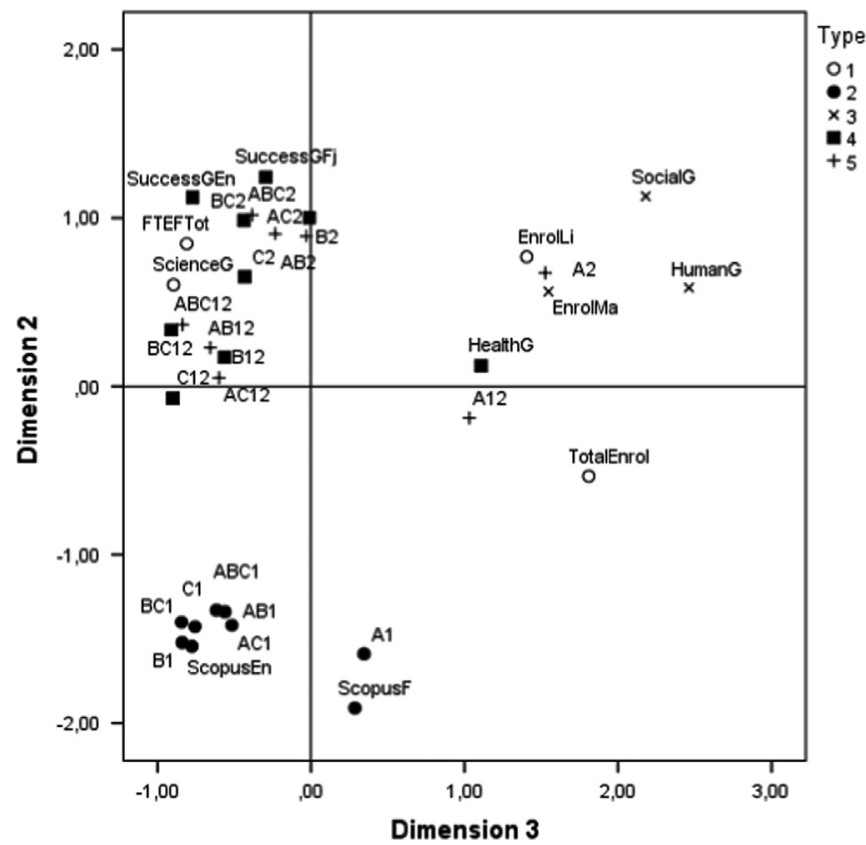

Fig. 2. INDSCAL: common map - projection on Dimension 2 and Dimension 3.

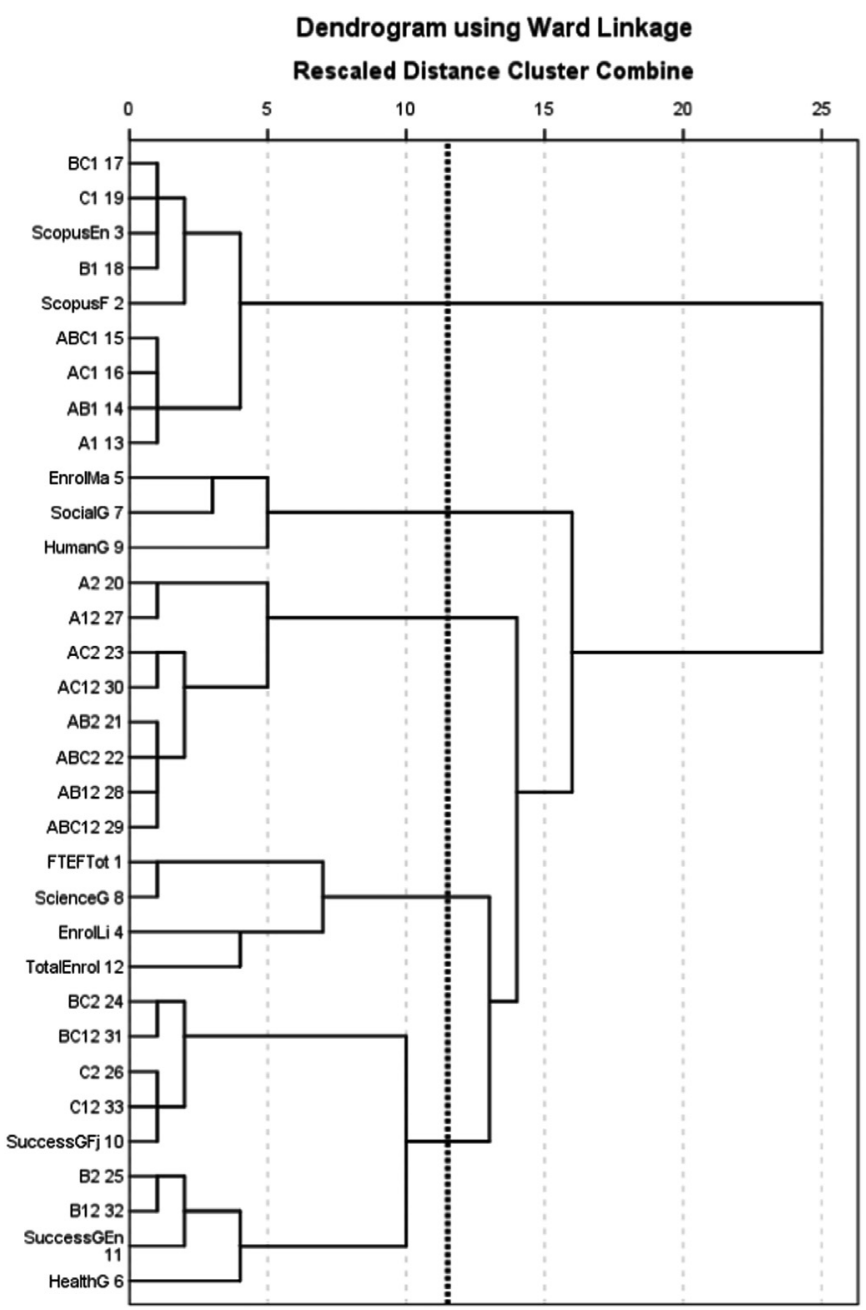

Fig. 3. Dendrogram for cluster analysis of variables.

Hierarchical Cluster Analysis. The coordinates in the sixdimensional space of each point have been treated as variables, each university being a case. The clustering algorithm chosen is the one proposed by Ward, which is akin to ANOVA in the sense that it maximises homogeneity within a cluster and heterogeneity between the clusters. The resulting dendrogram can be seen in Fig. 3.

The choice of the number of clusters to be detected from the figures is at the analysts' discretion. It seems clear that variables BC1, C1, ScopusEn, B1, ScopusF, ABC1, AC1, AB1, and A1 form a cluster. All of them have in common an association with research papers: the DEA specifications contain only research papers as an output, and the non-DEA variables are ratios that contain research papers in the numerator of their definition. This cluster can be seen in the lower right-hand corner of Fig. 1, and is associated with efficiency in research.

A second cluster of interest is formed by variables $A 2, A 12, A C 2$, $A C 12, A B 2, A B C 2, A B 12$, and $A B C 12$ (it can be found on the top lefthand corner of Fig. 1). All these variables contain input A (full time equivalent faculty) and output 2 (number of graduates). This cluster is associated with efficiency in teaching. It is interesting to notice that the full DEA model ABC12 belongs to this cluster.

The next cluster contains an important variable: the size of the university as measure through Total Enrolment. We see that this is related to the proportion of students who enrol in degree programmes (EnrolLi), the proportion of the programmes that are Science based (ScienceG) and the proportion of lecturing staff who 
are employed full-time (FTEFTot). This suggests that, as revealed by the statistics, large universities tend to concentrate on Science subjects, offer degree programmes - rather than master programmes -, and tend to employ a larger proportion of their lecturing staff full-time.

The remaining variables B2, B12, SuccessGEn, and HealthG -can really be subdivided into two groups. The first subgroup - $B C 2$, $\mathrm{BC} 12, \mathrm{C} 2, \mathrm{C} 12$, SuccessGFj - contains input C (first joining graduates) and output 2 (graduates). DEA specifications in the second subgroup contain input B (total enrolment) and output 2 (graduates) as well as the ratios Total graduates/total enrolment (Success Gen) and HealthG (Graduates in Health/total graduates). The variables in both subgroups indicate an association with successful progress through the degree.

The way in which ratios cluster with DEA results reveal the close connection that exists between ratio analysis and DEA as demonstrated in DEA-R models [36,8]. Indeed, some of the DEA models estimated collapse into a simple ratio. This happens, for example, with model A1 which includes as an input the number of academics and as an output the number of Scopus papers published. In the same cluster as A1 we find the ratio of Scopus papers/ Full time equivalent faculty (ScopusF). However, although both the ratio and the DEA model contain the same variables in the numerator and the denominator, the ratio is the direct value observed, while the DEA model contains efficiencies derived from the ratio.

\section{Case studies}

Up to now we have concentrated in how variables (ratios and efficiencies) are related to each other. This is interesting but it is not the objective of this paper. The objective of the paper is to assess, for each individual university, if there have been changes in efficiency in teaching and efficiency in research as a result of the policy drive of the Mexican government.

The study of the changes in efficiency that have taken place in individual universities during the period 2007-2012 requires a methodology that is described in Appendix B.

In brief, a vector of unit length in the six-dimensional space is associated with each university in each year. The vector always starts in the centre of coordinates of the common map. A line through the configuration is associated with this vector. Since we cannot work with representations in the six dimensional space, we have to work with projections on to pairs of dimensions. Take, for example, the National Autonomous University of Mexico (UNAM), the principal Mexican university, in 2010. The end point of the projection of the relevant unit vector in Dimensions 1 and 2 is shown in Fig. 4. The further away this end point is from the centre of coordinates in the figure, the more relevant is the interpretation derived from examining Fig. 4. The end point of the unit vector associated with UNAM2010 is to be found at the lower left hand corner of the figure. If we project the points associated with the 33 variables on the line that joints the point UNAM2010 with the origin of coordinates, we find - moving from the bottom up -, first the variables associated with research and teaching efficiency, indicating that UNAM was, in 2010, a university that was highly efficient at both teaching and research. As we move up we find that variables SuccesGF and SuccessGEn, project near the centre of coordinates, indicating that, in 2010, UNAM was fairly average in terms of converting registered students into graduates. At the other end of this imaginary line we find the projection of the variable FTEFTot, indicating that the proportion of full time aca-demics over total faculty was rather low in 2010.

If we look at the points associated with UNAM in Fig. 1 UNAM07, UNAM08, UNAM09, UNAM10, UNAM112, and UNAM12

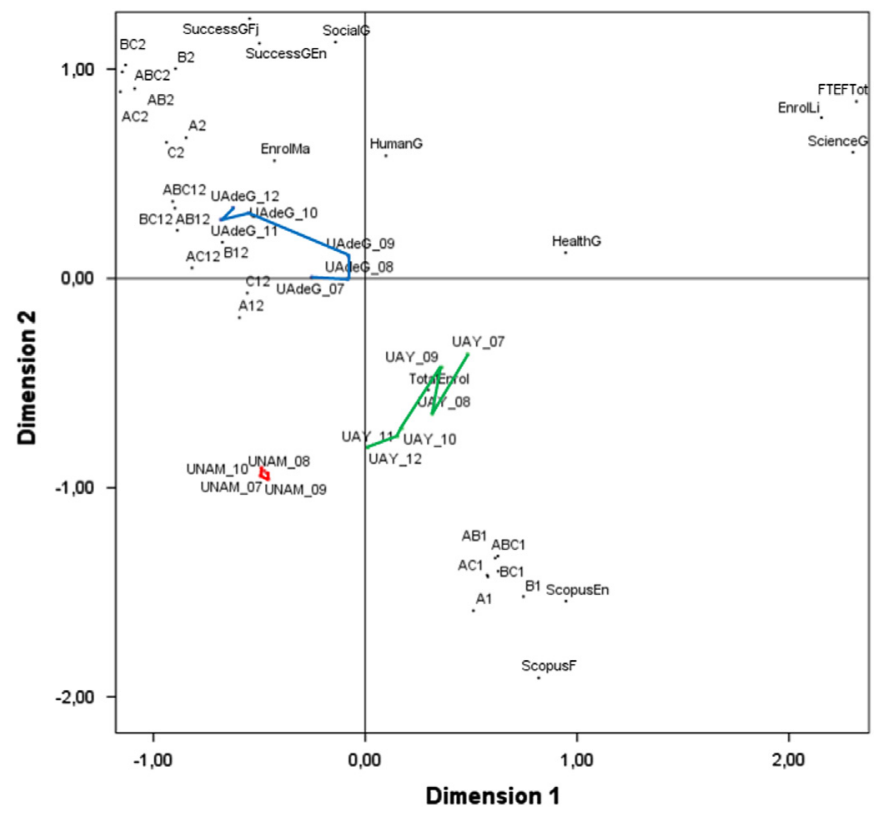

Fig. 4. Evolution of 4 Mexican universities through the common space (projection on Dimensions 1 and 2).

we observe that they remain very close together, indicating that there has been very little change in terms of teaching and research efficiency at this university over the period examined. In fact, UNAM appears to have been consistently good in terms of research and teaching efficiency, during the six years examined. Since efficiency is a comparative concept, this means that UNAM has not lost its place in the research and teaching rankings, even after taking into account the improvements observed at other universities.

Besides UNAM in 2010 we have projected on Fig. 4 two other universities: Universidad Autónoma de Yucatán (UAY) and Universidad Autónoma de Guadalajara (UAdeG). UNAM is a federal university; UAY is a local state university; and UAdeG is a private university. This gives us a variety of institutional frameworks.

We will now apply the same procedure to the study of UAdeG. We notice that the point UAdeG07 is located very near the origin of coordinates, indicating that in 2007 efficiency was not a major issue for this university. But the remaining points for this university are located more or less along the same line that joins the points to the origin of coordinates. UAdeG has not changed its position on the research and teaching league tables over the years, but it has become more focused on them. In fact, UAdeG has demonstrated to be very efficient at teaching, as shown by the projection of efficiency models that contain output 2 (graduates) on the line that joins points, such as UAdeG2012 to the origin of coordinates. Indeed, UAdeG2012 scores 1.2 in the standardised value of efficiency in model $A B C 2,1.3$ in model $A C 2$, and 1.5 in $B C 2$ indicating that it is better than average at producing graduates after taking into account the number of registrations.

Finally, we will discuss the case of UAY. The points associated with this university move down and towards the left in Fig. 4, something that is consistent with improvements in research efficiency. This is confirmed by an examination of the raw data. For example, the standardised value of efficiency under model ABC1 changes from 0.24 in 2007 to 1.63 in 2012 indicating a major effort in the direction of research quality.

The procedure described here is totally general and can be applied to any three-way data set (variables, cases, years). Examples of its application in other fields are: Mar-Molinero, Serrano Cinca [32] in the context of bank failure; Sagarra et al. [46] also in 
the context of bank failure; Mar-Molinero et al. [33] who studied the distress of a major UK company over time; Xie [58] in the context of population change in a UK city; and Serrano-Cinca et al. [52] who used it to study European financial integration. In this particular case, the methodology was employed to assess the efficiency evolution of all Mexican universities between 2007 and 2012. The evolution of all Mexican universities in the data set was studied, but we feel unnecessary to represent the 385 points (55 universities over six years) in the map. This is the kind of exercise that is to be done university by university as part of a dialogue between government administrators and university authorities.

\section{Conclusions and discussion}

Governments spend large amounts of resources for the promotion of common good. A good example is education. Large amounts of data, in the form of official statistics, are collected in order to assess the success or otherwise of national policies. There is a need to analyse this data in a form that can be understood by individuals who are not conversant with the intricacies of mathematical statistics.

Starting in 1989, Mexico has made a great effort in order to improve the quality and quantity of university education. In this paper we have asked the question of whether, on the basis of official statistics, we can assess if the extra resources have also improved the efficiency with which universities deliver their joint products of teaching and research. This is to say: are resources better employed? Clearly, this question needs to be answered university by university, since each institution has different ways of planning and decision making. We have developed a metho-dology that combines DEA and scaling in the production of sta-tistical maps to reveal at a glance how a university has evolved in this efficiency framework.

The analysis has been based on 33 variables (12 of them standard ratios, and 21 different definitions of efficiency) for 55 universities over a six-year period (2007-2012). Because of the large amount of data involved, we have chosen to concentrate on the relationship between variables. A potential extension of this work resides into a closer analysis of time trends in the efficiency results. Specifically, some recent papers did explore how the efficiency and productivity of universities do vary over time, both with non-parametric and parametric techniques (see García-Aracil [10] and Agasisti, 2015 respectively). A notable contribution in the field is the one proposed by Johnson and Ruggiero [19], who decompose efficiency scores' variation over time in three compo-nents: pure efficiency change, frontier shifts (technological varia-tion) and change in environmental conditions. In the approach developed in this paper, the inclusion of contextual (environ-mental) variables would substantially improve the empirical analysis, by allowing to understand how much the performance of the various universities - and their clustering around specific characteristics - is affected by phenomena that are beyond the ability of HE managers to influence them. This extension is then left for future research, which will primarily consist in selecting and adding such variables into the empirical study. Moreover, the primary scope of the present paper is to assess the relationship between ratios and DEA scores, and combine them through Multidimensional Scaling - while the primary objective of a future study will be assessing how the selected ratios and DEA scores are jointly affected by including contextual variables.

Turning back to this paper, we have represented the relation-ship between the variables in a six dimensional map. It has been found that efficiency effects can be observed in the projection of the sixdimensional configuration into the first and the second dimensions. Into the selected dimensional map, we have projected three universities in order to illustrate how policy analysis can be carried out.

The three universities whose policies have been analysed are: the National Autonomous University of Mexico (UNAM), the Autonomous University of Guadalajara (UAdeG), and the Autonomous University of Yucatan (UAY). These universities have been selected for discussion because they illustrate different aspects of the findings.

UNAM is the principal Mexican university, and one of the top Latin American Higher Education institutions [38]. We have observed that this is a reference university for both teaching and research and that it has remained fully efficient over the whole period studied.

UAdeG, appears to have scored high in terms of the use put to teaching resources, whilst being rather "middle of the road" in terms of research efficiency. This appears to be true all through the period studied. But, our analysis also shows that the importance of efficiency, as described here, has been emphasised year after year. This is consistent with the policy, stated in the university's web-site, of emphasising academic excellence as a result of a strategic plan that has its roots in 2008 and that is still guiding decisions on physical infrastructure, equipment, and curriculum design.

Finally, UAY, as a result of a self-assessment exercise [42], identified a series of weak aspects that considered important to correct. This guided an Institutional Development Plan [41] that prioritised research training for academics, and more appropriate student curricula. The success of this policy can be observed in Fig. 4 where UAY can be seen clearly moving towards the areas associated with higher efficiency in research in the statistical configuration.

\section{Acknowledgements}

The authors wish to thank Holiver Romero Flores and Esteban Paz Cruz from Asociación Nacional de Universidades e Institu-ciones de Educación Superior (ANUIES) in Mexico, and Viviana Elizabeth Zárate Mirón from Universidad Popular Autónoma del Estado de Puebla, for their help with creating the database on which this study is based. The authors also acknowledge support from Project ECO2010-21393-C04-01 financed by the Spanish Ministry of Science and Innovation.

\section{Appendix A}

\begin{tabular}{lll}
\hline Abbreviation & Institution & Type \\
\hline BUAP & BENEMERITA UNIVERSIDAD AUTONOMA DE PUEBLA & State University \\
IPN & INSTITUTO POLITECNICO NACIONAL & Federal University \\
ITAM & INSTITUTO TECNOLOGICO AUTONOMO DE MEXICO & Private University \\
ITSON & INSTITUTO TECNOLOGICO DE SONORA & State University
\end{tabular}




\begin{tabular}{|c|c|}
\hline ITESO & INSTITUTO TECNOLOGICO Y DE ESTUDIOS SUPERIORES DE OCCIDENTE \\
\hline ITESM & SISTEMA INSTITUTO TECNOLOGICO Y DE ESTUDIOS SUPERIORES DE MONTERREY \\
\hline ANAHUAC & SISTEMA UNIVERSIDAD ANAHUAC \\
\hline UVM & SISTEMA UNIVERSIDAD DEL VALLE DE MEXICO \\
\hline IBERO & SISTEMA UNIVERSIDAD IBEROAMERICANA \\
\hline LASALLE & SISTEMA UNIVERSIDAD LA SALLE, AC \\
\hline UAAN & UNIVERSIDAD AUTONOMA AGRARIA ANTONIO NARRO \\
\hline UBJOAX & UNIVERSIDAD AUTONOMA BENITO JUAREZ DE OAXACA \\
\hline $\mathrm{UACH}$ & UNIVERSIDAD AUTONOMA CHAPINGO \\
\hline UAAGS & UNIVERSIDAD AUTONOMA DE AGUASCALIENTES \\
\hline UABC & UNIVERSIDAD AUTONOMA DE BAJA CALIFORNIA \\
\hline UABCS & UNIVERSIDAD AUTONOMA DE BAJA CALIFORNIA SUR \\
\hline UACAMP & UNIVERSIDAD AUTONOMA DE CAMPECHE \\
\hline UACHIS & UNIVERSIDAD AUTONOMA DE CHIAPAS \\
\hline UACHIH & UNIVERSIDAD AUTONOMA DE CHIHUAHUA \\
\hline UACJ & UNIVERSIDAD AUTONOMA DE CIUDAD JUAREZ \\
\hline UACOAH & UNIVERSIDAD AUTONOMA DE COAHUILA \\
\hline UAdeG & UNIVERSIDAD AUTONOMA DE GUADALAJARA \\
\hline UAGRO & UNIVERSIDAD AUTONOMA DE GUERRERO \\
\hline UNACAR & UNIVERSIDAD AUTONOMA DEL CARMEN \\
\hline UAHGO & UNIVERSIDAD AUTONOMA DEL ESTADO DE HIDALGO \\
\hline UAEM & UNIVERSIDAD AUTONOMA DEL ESTADO DE MEXICO \\
\hline UAEMOR & UNIVERSIDAD AUTONOMA DEL ESTADO DE MORELOS \\
\hline UANAY & UNIVERSIDAD AUTONOMA DE NAYARIT \\
\hline UANL & UNIVERSIDAD AUTONOMA DE NUEVO LEON \\
\hline UAQRO & UNIVERSIDAD AUTONOMA DE QUERETARO \\
\hline UASLP & UNIVERSIDAD AUTONOMA DE SAN LUIS POTOSI \\
\hline UASIN & UNIVERSIDAD AUTONOMA DE SINALOA \\
\hline UATAMPS & UNIVERSIDAD AUTONOMA DE TAMAULIPAS \\
\hline UATLAX & UNIVERSIDAD AUTONOMA DE TLAXCALA \\
\hline UAY & UNIVERSIDAD AUTONOMA DE YUCATAN \\
\hline UAZAC & UNIVERSIDAD AUTONOMA DE ZACATECAS \\
\hline UAM & UNIVERSIDAD AUTONOMA METROPOLITANA \\
\hline UCOL & UNIVERSIDAD DE COLIMA \\
\hline UGUAD & UNIVERSIDAD DE GUADALAJARA \\
\hline UGTO & UNIVERSIDAD DE GUANAJUATO \\
\hline UDLAP & UNIVERSIDAD DE LAS AMERICAS PUEBLA, AC \\
\hline UDEFA & UNIVERSIDAD DEL EJERCITO Y FUERZA AEREA \\
\hline UDEM & UNIVERSIDAD DE MONTERREY \\
\hline UQROO & UNIVERSIDAD DE QUINTANA ROO \\
\hline UNISON & UNIVERSIDAD DE SONORA \\
\hline UINTERCON & UNIVERSIDAD INTERCONTINENTAL \\
\hline UAJTAB & UNIVERSIDAD JUAREZ AUTONOMA DE TABASCO \\
\hline UJDGO & UNIVERSIDAD JUAREZ DEL ESTADO DE DURANGO \\
\hline UMSNH & UNIVERSIDAD MICHOACANA DE SAN NICOLAS DE HIDALGO \\
\hline UNAM & UNIVERSIDAD NACIONAL AUTONOMA DE MEXICO \\
\hline UP & UNIVERSIDAD PANAMERICANA \\
\hline UPAEP & UNIVERSIDAD POPULAR AUTONOMA DEL ESTADO DE PUEBLA \\
\hline UR & UNIVERSIDAD REGIOMONTANA, AC \\
\hline UNITEC & UNIVERSIDAD TECNOLOGICA DE MEXICO \\
\hline UV & UNIVERSIDAD VERACRUZANA \\
\hline
\end{tabular}

Private University Private University Private University Private University Private University Private University Federal University State University Federal University State University State University State University State University State University State University State University State University Private University State University State University State University State University State University State University State University State University State University State University State University State University State University State University Federal University State University State University State University Private University Federal University Private University State University State University Private University State University State University State University Federal University Private University Private University Private University Private University State University

\section{Appendix B}

This appendix describes the methodology employed in the study of the changes that have taken place in individual universities and how such changes are related to the variables used in the analysis.

It is standard practice in FA and MDS to plot cases in a statistical map and identify directions in which a particular characteristic of the data, normally the value of a variable, increases. A few examples that use this approach in order to interpret the results obtained are Sagarra et al. [46], Gutiérrez-Nieto et al. [12], and Serrano-Cinca et al. [51]. The mathematical basis for procedure employed can be found in Mar-Molinero and Mingers [34]. The methodology employed here extends this approach. This is so because the statistical algorithm represents variables in the space, and not cases. It is a necessary development since the number of cases can be very large, but the number of variables stays normally between reasonable limits. 
The position of the variables in the space is given by a set of coordinates. In the present study, each variable has been plotted in a six dimensional space; hence each variable is associated with six numbers, which we will call "dimensions". The algorithm automatically standardises the dimensions to mean zero and unit variance. This explains why the scales in Fig. 1 range from -3 to +3 . To represent cases in the variables configuration requires several steps.

Step 1. - Variables need to be standardised in order to make the results unit-independent. In this study we work with 33 variables, and all 33 are standardised to mean zero and variance 1 .

Step 2. - We select a particular case, say the National Autonomous University of Mexico in 2007 (UNAM2007). Our hypothesis is that the values of the 33 standardised variables of the UNAM in 2007 can be explained in relation to the statistical configuration derived from the analysis. This means that the position of the variables in the configuration explain the values of the 33 standardised variables for UNAM2007. For simplicity we use a linear regression equation.

UNAM $2007=\beta_{0}+\beta_{1} \operatorname{Dim} 1+\beta_{2} \operatorname{Dim} 2+\beta_{3} \operatorname{Dim} 3+\beta_{4} \operatorname{Dim} 4+\beta_{5} \operatorname{Dim} 5+\beta_{6} \operatorname{Dim} 6+$ error

Where UNAM2007 is a column vector whose elements are the standardised values of the 33 variables for UNAM in 2007 . Dim1 is the column vector that contains the first coordinate of the 33 variables in the common map. The other regressors are to be understood in the same way.

When this regression is estimated, an adjusted $R^{2}$ of 0.824 is found. If the adjusted $R^{2}$ had been "low", we would have concluded that the configuration does not explain well the observed variable values for UNAM2007. We normally take adjusted $R^{2}$ values of less than 0.5 as being "low". In this case we conclude that the six-dimensional configuration is an appropriate tool with which to interpret UNAM in 2007.

Step 3. - We draw a line through the origin of coordinates in the direction of vector

$\left(\beta_{1}, \beta_{2}, \beta_{3}, \beta_{4}, \beta_{5}, \beta_{6}\right)$

Notice that we have not included the constant term in the vector.

Step 4. - The line thus produced is associated with UNAM2007. Standardised values of the variables of UNAM2007 can be estimated by projecting the points in the configuration on to the line. Clearly, both the configuration and the line are drawn in a six-dimensional space and we need to work with projections into two coordinates, as done in Fig. 5 where we have projected only six variables on to the line as an illustration.

We can imagine a scale associated with the line we have just drawn. The zero of the scale is in the centre of coordinates of the configuration. As we move towards one end of the line, the scale increases (normally from zero to three), and as we move towards the other end, the scale decreases (normally from zero to minus three). In the case represented in Fig. 5, positive values are associated with a South West direction, while negative values are associated with a North East direction. Moving from top to bottom we find FTEFTot, SocialG, $\mathrm{ABC} 12, \mathrm{~A} 12, \mathrm{AB} 1$, and ScopusF. The values these variables take for UNAM2007 are $-0.99,-1.20,1.11,2.14,1.85$, and 3.49. The ordering of the projections over the line is in line with the ordering of the observed standardised values, although the match is not perfect. If the match had been perfect, we would have found a value of the adjusted $R^{2}$ much closer to unity.

Step 5. - Although the above method represents cases in the variables space, it has two disadvantages: first, if we have many cases, the figure will be full of straight lines and it will be difficult to appreciate what is special about every case; second, the projection on two dimensions of a straight line in a six-dimensional space is a straight line, and it does not give information about the inclination of the line with respect to the plane on which it is projected. To try to overcome these problems we also draw a unit vector in the direction of increasing values associated with the line. If the unit vector is contained within the plane in which it projects - in this case Dimension 1 and Dimension $2-$, the projection of the unit vector has a length of 1 . The higher the inclination of the unit vector with respect to the plane, the shorter will the projection of the vector. Since all the unit vectors start from the centre of coordinates, it is only necessary to locate the end point of the projection, and this is what has been done in the main text of the paper. In Fig. 5 we have drawn both the line and the projection of the unit vector associated with the line. Such end point is labelled UNAM2007.

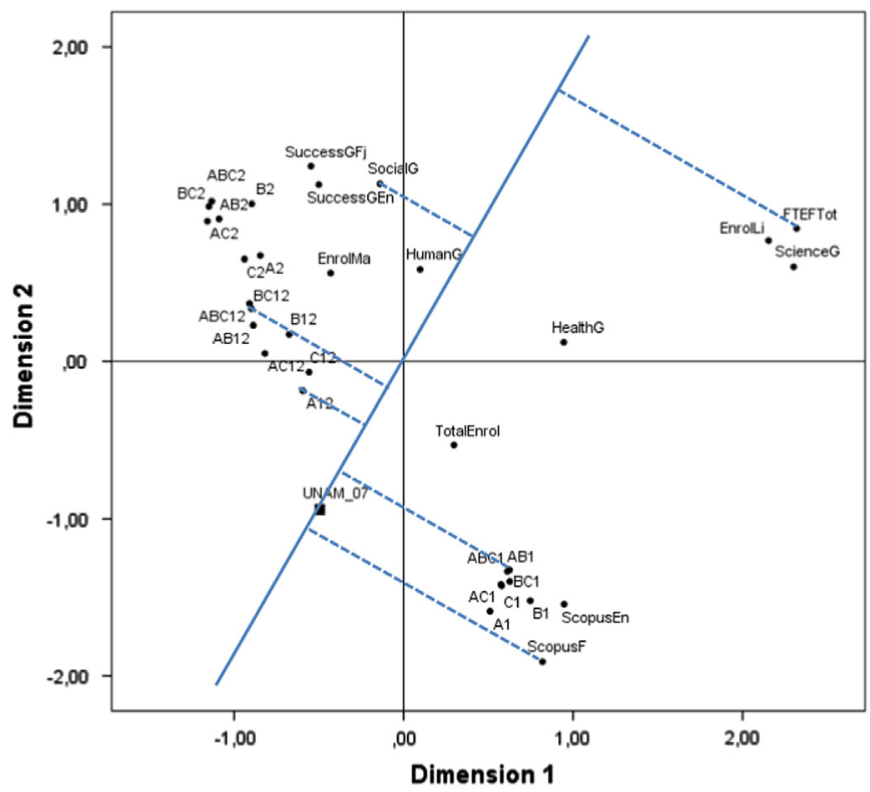

Fig. 5. Interpreting cases in the light of the configuration estimated. 


\section{References}

[1] Ahn T, Arnold V, Charnes A, Cooper WW. DEA and ratio efficiency analysis for public institutions of higher learning in Texas. Research in Government and Non-profit Accounting 1989;5:165-85.

[2] Beasley JE. Determining teaching and research efficiencies. Journal of the Operational Research Society 1995:441-52.

[3] Carroll JD, Chang JJ. Analysis of individual differences in multidimensional scaling via an $\mathrm{N}$-way generalization of "Eckart-Young" decomposition. Psychometrika 1970;35:283-319.

[4] Chen WC, McGinnis LF. Reconciling ratio analysis and DEA as performance assessment tools. European Journal of Operational Research 2007:178:277-91.

[5] Consejo Nacional de Población (CONAPO). 〈http://www.conapo.gob.mx/es/ CONAPO/Proyecciones_de_la_Poblacion_2010-2050 $\rangle$; [accessed 7.09.2013].

[6] Coxon A. The user's guide to multidimensional scaling. London: Heinemann Educational Books; 1982.

[7] De Witte K, Lopez-Torres L. Efficiency in education. A review of literature and a way forward. Journal of Operational Research Society; 2016. [in press].

[8] Despic O, Despic M, Paradi J. DEA-R: ratio-based comparative efficiency model, its mathematical relation to DEA and its use in applications. Journal of Productivity Analysis 2007;28:33-44.

[9] Diamond AM, Medewitz JN. Use of DEA in an evaluation of the efficiency of the DEEP program for Economic education. Journal of Economic Education 1990;21:337-54.

[10] García-Aracil A. Understanding productivity changes in public universities: evidence from Spain. Research Evaluation 2013;22(5):351-68.

[11] Gereffi G. Development models and industrial upgrading in China and Mexico. European Sociological Review 2009;25:37-51.

[12] Gutiérrez-Nieto B, Serrano-Cinca C, Mar-Molinero C. Microfinance institutions and efficiency. Omega: The International Journal of Management Science 2007;35:131-42.

[13] Harshman RA. Foundations of the PARAFAC procedure: models and conditions for an explanatory multimodal factor analysis. UCLA Working Papers in Phonetics. $16 ; 1970$. p. 1-84.

[14] Jenkins L, Anderson M. A multivariate statistical approach to reducing the number of variables in data envelopment analysis. European Journal of Operational Research 2003;147:51-61.

[15] Johnes G. Johnes J. Measuring the research performance of UK economics departments: an application of data envelopment analysis, 1993 Oxford Economic Papers 45 (2), p. 332-347.

[16] Johnes J.16 Efficiency measurement. International handbook on the economics of education; 2004. p. 613

[17] Johnes J. Data envelopment analysis and its application to the measurement of efficiency in higher education. Economics of Education Review 2006;25 (3):273-88.

[18] Johnes J. Efficiency and productivity change in the English higher education sector from 1996/97 to 2004/5*. The Manchester School 2008;76(6):653-74.

[19] Johnson AL, Ruggiero J. Nonparametric measurement of productivity and efficiency in education. Annals of Operational Research 2014;221(1):197-210.

[20] Jones CL. A note on the use of directional statistics in weighted Euclidean distances multidimensional scaling. Psychometrika 1983;48:473-6.

[21] Kent-Serna R. Las Políticas de Educación Superior en México durante la Modernización. México, DF: ANUIES; 2009

[22] Kiers HAL. An overview of three-way analysis and some recent developments. In: Rizzi A, Vichi M, Bock $\mathrm{HH}$, editors. Advances in data science and classification. Berlin: Springer; 1998. p. 592-602.

[23] Kruskal JB. Non-metric multidimensional scaling: a numerical method. Psychometrika 1964;29:115-29.

[24] Kruskal JB, Wish M. Multidimensional scaling. London, UK: Sage; 1984.

[25] Liu JS, Lu LYY, Lu WM, Lin BJY. A survey of DEA applications. Omega 2013;41:893-902.

[26] Liu WB, Zhang DQ, Meng W, Li XX, Xu F. A study of DEA models without explicit inputs. Omega 2011;39:472-80.

[27] Liu JS, Lu WM. DEA and ranking with the network-based approach: a case of R\&D performance. Omega 2010;38:453-64.

[28] López MD, Lagunes CA, Recio CE. Políticas públicas y educación superior en México. Paper presented to the " $X$ Congreso Nacional de Investigación Educativa" that took place in Veracruz. 〈http://www.comie.org.mx/congreso/ memoriaelectronica/v10/pdf/area_tematica_09/ponencias/1480-F.pdf); 2009.

[29] MacCallum RC. Transformation of a three-mode multidimensional scaling solution to INDSCAL form. Psychometrika 1976;41:385-400.

[30] Mar-Molinero C. A multidimensional scaling analysis of the 1986 ratings of universities in the UK. Higher Education Review 1989;21:7-25.

[31] Mar-Molinero C. Understanding university undergraduate applications. Higher Education Review. 1990;22:7-23.

[32] Mar-Molinero C, Serrano Cinca C. A multivariate analysis of bank failure in Spain. European Journal of Finance 2001;7:165-83.

[33] Mar-Molinero C, Bishop H, Turner M. The distress of Marks and Spencers PLC in 2001: a multidimensional scaling analysis. Cuadernos de Estudios Empresariales 2005;15:107-26.
[34] Mar-Molinero C, Mingers J. Mapping MBA programmes: an alternative analysis. Journal of the Operational Research Society 2006;58:874-86.

[35] Mar-Molinero C, Portillo F. Analysing the success of MBA programmes. Journal of Strategic Management Education 2010;6:158-76.

[36] Mozaffari MR, Gerami J, Jablonsky J. Relationship between DEA models without explicit inputs and DEA-R models. Central European Journal of Operational Research 2014;22:1-12.

[37] Norman M, Stocker B. Data envelopment analysis: the assessment of performance. Chichester, UK: John Wiley and Sons; 1991.

[38] Ordorika I, Pusser B. La máxima casa de estudios: the Universidad Naciona Autónoma de México as a State-Building University. In: Comparative education: ASHE reader series. 2nd editionPearson Learning Solutions; 2010. p. 396-411.

[39] Parkin D, Hollingsworth B. Measuring production efficiency in acute hospitals in Scotland, 1991-1994: validity issues in data envelopment analysis. Applied Economics 1997;29:1425-33.

[40] Pastor JT, Ruiz JL, Sirvent I. A statistical test for nested radial DEA models. Operations Research 2002;50:728-35.

[41] PDI. Plan de desarrolo institucional. Documento institucional. Mérida, México: Universidad Autónoma de Yucatán; 2010-2020.

[42] PIFI. Programa integral de fortalecimiento institucional. Documento oficial. Mérida: Universidad Autónoma de Yucatán; 2001.

[43] Pounder J. Institutional performance in higher education: is quality a relevant concept? Quality Assurance in Education 1999;7(3):156-65.

[44] Premachandra IM. A note on DEA vs principal component analysis: an improvement to Joe Zhu's approach. The European Journal of Finance 2001;132:553-60.

[45] Ramsay JO. Some statistical approaches to multidimensional scaling data. Journal of the Royal Statistical Society, A 1982;145:285-312.

[46] Sagarra M, Mar-Molinero C, García-Cestona M. Spanish savings banks in the credit crunch: could distress have been predicted before the crisis? A multivariate statistical analysis The European Journal of Finance 2015;21(3):195214.

[47] Sagarra M, Mar-Molinero C, Rodríguez-Regordosa H. Evaluating the success of educational policy in Mexican Higher Education. Higher Education 2015;69 (3):449-69.

[48] Schiffman JF, Reynolds ML, Young FW. Introduction to multidimensional scaling: theory, methods, and applications. London: Academic Press; 1981.

[49] Segovia MM, Contreras I, Mar-Molinero C. A DEA analysis of risk, cost, and revenues in insurance. Journal of the Operational Research Society 2009;60:1483-94.

[50] Serrano-Cinca C, Mar-Molinero C. Selecting DEA specifications and ranking units via PCA. Journal of the Operational Research Society 2004;55:521-8.

[51] Serrano-Cinca C, Mar-Molinero C, Bossi-Queiroz A. An approach to the measurement of intangible assets in public sector using scaling techniques. Journal of Intellectual Capital 2003;4:249-75.

[52] Serrano-Cinca C, Mar-Molinero C, Gallizo JL. A multivariate study of the EU economy via financial statements analysis. Journal of the Royal Statistical Society, D 2002;51:335-54

[53] Simar L, Wilson PW. Sensitivity analysis of efficiency scores: How to bootstrap in nonparametric frontier models. Management Science 1998;44:49-61.

[54] Thanassoulis E, Kortelainen M, Johnes G, Johnes J. Costs and efficiency of higher education institutions in England: a DEA analysis. Journal of the Operational Research Society 2011;62(7):1282-97.

[55] Tomkins C, Green R. An experiment in the use of DEA for evaluating the efficiency of UK university departments of accounting. Financial Accountability and Management 1988;4:147-64.

[56] Tucker LR. Some mathematical notes on three-mode factor analysis. Psychometrika 1966;31:279-311.

[57] UNAM. Estudio Comparativo de las Universidades Mexicanas (ECUM). México: UNAM, Dirección General de Evaluación Institucional; 2013.

[58] Xie AJ. A multivariate analysis of census data to explore changes in the population structure of Canterbury, UK. UK: Management School, University of Kent; 2012.

[59] Yin Y, Yasuda K. Similarity coefficient methods applied to the cell formation problem: a taxonomy and review. International Journal of Production Economics 2006;101:329-52.

[60] Young FW. Enhancements in ALSCAL-82. In: Proceedings of the seventh annual SAS users group. Cary, NC: The SAS Institute; 1982. p. 633-42.

[61] Young FW, Harris DF. Multidimensional scaling. In: Norusis MJ, editor. SPSS professional statistics 6.1. Chicago: SPSS Inc; 1994.

[62] Worthington AC. An empirical survey of frontier efficiency measurement techniques in education. Education economics 2001;9(3):245-68. 